\title{
TRIBUTE to Jean Henri ALEXANDRE—now leaving the EHS board
}

\author{
F. Corcione ${ }^{1,2}$
}

Received: 13 February 2018 / Accepted: 16 February 2018 / Published online: 13 March 2018

c) Springer-Verlag France SAS, part of Springer Nature 2018

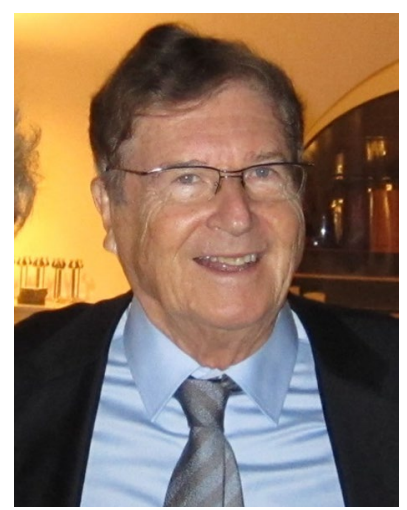

"Count your age by friends, not years.

Count your life by smiles, not tears."

\section{J. Lennon}

I would like to "honor" a great surgeon, a great man, a great friend. He is now leaving the board of European Hernia Society (EHS) on which he has served for many years. $\mathrm{He}$ is one of the founders of the Society and has also been on the Editorial Board of Hernia Journal. He is a very well known and respected surgeon. I would like to thank Prof. Alexandre for all his contributions and for the development of modern hernia surgery. He is still a very active man and a devoted hernia specialist. To summarize his contributions for the development of hernia surgery is not easy considering the huge number of activities in the field as well as in general surgery as a whole.

In this tribute and greeting, I do not want to display what he accomplished. A search on "Google" will explore the evidence of his activity in all fields of surgery. Jean Henri

\footnotetext{
F. Corcione

francesco.corcione@ ospedalideicolli.it

Surgery Department, A.O.R.N. dei Colli, Naples, Italy

2 General Laparoscopic and Robotic Surgery, Monaldi Hospital, Naples, Italy
}

succeeded in acquiring the highest rank in the French healthcare organization and is also one of the most respected members of EHS being one of the founders of GREPA (Fig. 1).

My task is to describe Jean Henri based on my own experience and vision. I learnt to know him in 1981. I went to the department of surgery at Reims University as exchange student for 1 year hosted by Prof. Jean Rives. This was a very important year in my career both for cultural and surgical training. Prof. Rives was surely a great surgeon daily motivating us students to reach new goals. One day, our "patron" operated a friend of him that suffered a serious complication that got worse. Prof. Rives was deeply concerned and decided to transfer the patient to the hospital of Prof. J. H. Alexandre in Paris. We were told that he was the most respected surgeon he knew that could solve the problem. This was where my tremendous respect for Prof. J. H. Alexandre started. I later discovered they were longtime friends both sharing an Algerian origin.

Later I was appointed to work in Paris with Prof. J. H. Alexandre. Indeed, it was a gift to learn from this talented surgeon. He welcomed me with his gentle and elegant manner in his office in the old Broussais St. Joseph Hospital in the heart of Paris. I was impressed by how he handled fellows under training as well as patients; always serious, but with kindness and sweetness, and a touch of irony. We have all learned to appreciate his special qualities over the years. For me it started as a teacher/student relationship based on a great respect which developed into friendship.

Prof. J. H. Alexandre used to be a well reputed pancreatic and gastrointestinal surgeon, but devoted the end of his surgical career exclusively to abdominal wall surgery and has kept on working for its development long after his retirement. He has served on the board of EHS for many years and participated in several educational projects of EHS (Fig. 2). He also published "The Story of EHS-GREPA 1979-2014" that was presented at the 1st Word Conference on Abdominal Wall Hernia Surgery in Milan in 2015 [1]. He is still sollicited regularly on medicolegal aspects of surgery in France.

Jean Henri is a socially very active person, which has kept very fit physically and intellectually through the years with 


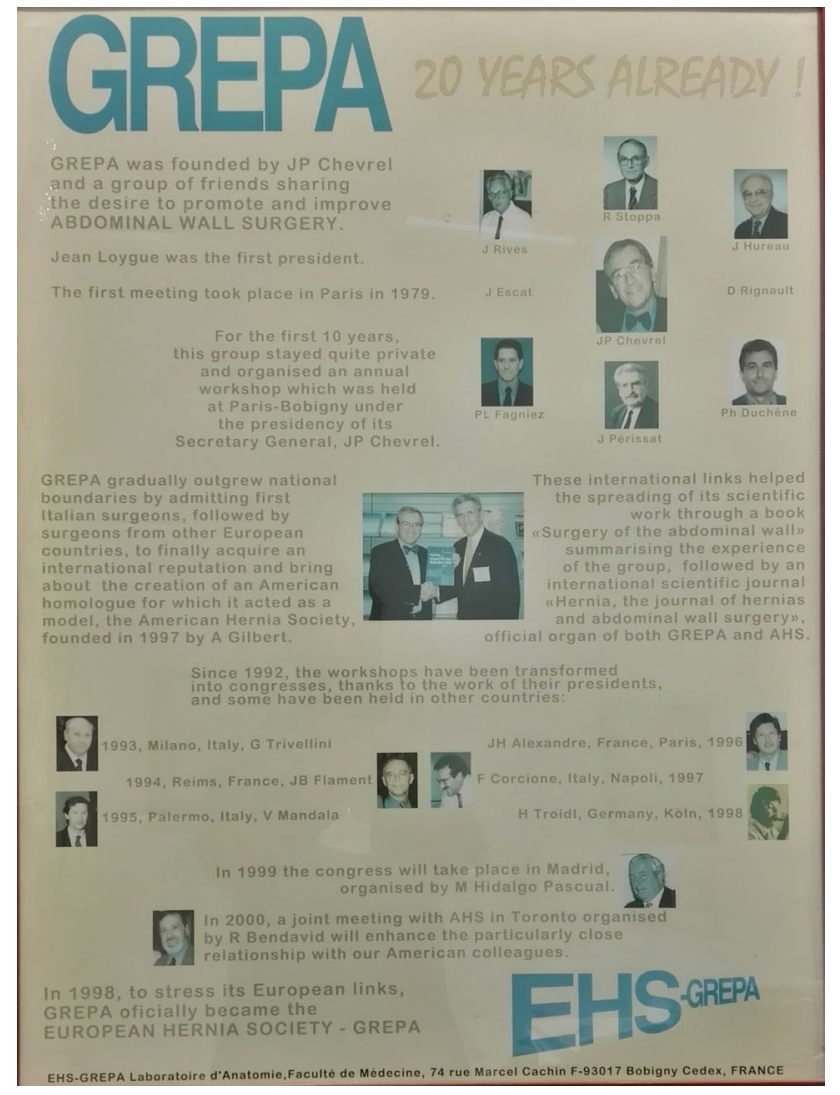

Fig. 1 Historical Poster for the 20th year of GREPA

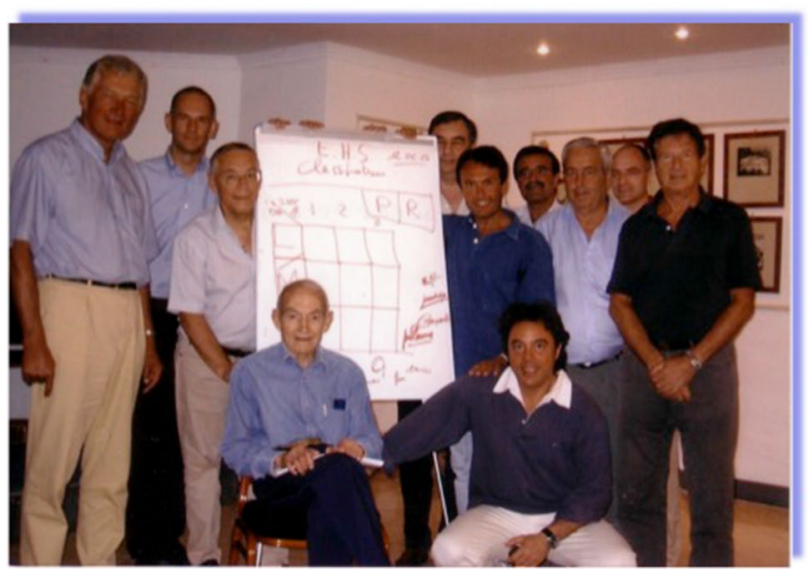

Fig. 2 EHS board meeting in Capri, Italy 2004

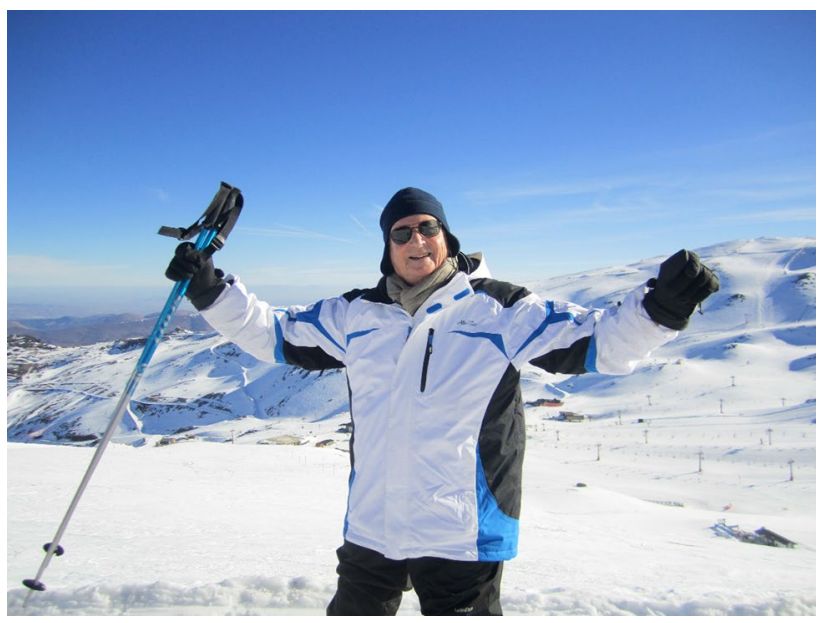

Fig. 3 Sporty and active Jean Henri at the Winter Meeting in Sierra Nevada, Spain 2015

a good eye for the beauty in life (Fig. 3). He is a respected, open-minded person and a man of brilliance that always accompanies those who aim at the top.

There are still unexplored areas to discover. I thank you for your inspiration and the encouragement that only sensitive and superior men can give. Thank you for what you did for French Surgery, European Surgery, Parietal Surgery and for your basic contribution to EHS and to me; I still keep your teachings and advice in my mind and in my heart.

Greetings from a dear friend

Francesco and all friends of EHS

Prof. Francesco Corcione

Past President of Italian Society of Surgery

Honorary Member of "Acadèmie Nationale de Chirurgie", Paris (Fr)

Chief of Surgery Department of "A.O.R.N. dei Colli"

Chief of U.O.C. General Laparoscopic and Robotic Surgery, Monaldi Hospital

\section{Reference}

1. Alexandre JH (2015) The story of EHS-GREPA 1979-2014. Hernia 19(3):349-354. https://doi.org/10.1007/s10029-015-1386-1 (Epub 2015 May 12) 